\title{
Dimensões da violência na Enfermagem: aplicação do questionário de atos negativos
}

\author{
Dimensions of violence in Nursing: application of the questionnaire of negative acts \\ Dimensiones de la violencia en Enfermería: aplicación del cuestionario de actos negativos
}

Recebido: 19/06/2021 | Revisado: 24/06/2021 | Aceito: 01/07/2021 | Publicado: 14/07/2021

\author{
Ellen Maria Hagopian \\ ORCID: https://orcid.org/0000-0001-5966-0159 \\ Universidade de São Paulo, Brasil \\ E-mail: ellenmaria@usp.br \\ Genival Fernandes de Freitas \\ ORCID: https://orcid.org/0000-0003-4922-7858 \\ Universidade de São Paulo, Brasil
}

\begin{abstract}
Resumo
Este estudo tem como objetivo identificar as dimensões da violência no trabalho da equipe de Enfermagem relacionadas aos atos negativos. Trata-se de um estudo quantitativo, exploratório, transversal. Com amostra estimada de 13.011 profissionais de Enfermagem, utilizou-se um questionário de atos negativos revisado. A variável de desfecho foi o escore do questionário, que permitiu a avaliação da violência em quatro dimensões. Para a análise dos dados, foi utilizada a análise descritiva por médias, desvios-padrão, valores mínimos e máximos dos escores das variáveis contínuas e proporções para as variáveis qualitativas. A taxa de participação foi de $16,4 \%$, correspondente a 2.136 profissionais. A desqualificação pessoal e profissional foi a dimensão que apresentou a maior média de pontuação seguida, respectivamente, pelo assédio relacionado ao trabalho, assédio pessoal e intimidação física. A partir da identificação e pontuação dos atos negativos referenciados no instrumento aplicado, foi possível identificar as dimensões da violência no cotidiano dos profissionais da Enfermagem.

Palavras-chave: Violência no trabalho; Equipe de enfermagem; Ambiente de trabalho; Ética em enfermagem; Comportamento social.
\end{abstract}

\begin{abstract}
This study aims to identify the dimensions of work violence in the Nursing team related to negative acts. This is a quantitative, exploratory, cross-sectional study. With an estimated sample of 13,011 Nursing professionals, a revised negative acts questionnaire was used. The outcome variable was the questionnaire score, which allowed the evaluation of violence in four dimensions. For the data analysis, a descriptive analysis by means, standard deviations, minimum and maximum values of the scores of the continuous variables and proportions for the qualitative variables was used. The participation rate was $16.4 \%$, corresponding to 2,136 professionals. Personal and professional disqualification was the dimension with the highest average score followed, respectively, by work-related harassment, personal harassment, and physical intimidation. From the identification and scoring of the negative acts referenced in the instrument applied, it was possible to identify the dimensions of violence in the daily lives of nursing professionals.
\end{abstract}

Keywords: Workplace violence; Nursing team; Working environment; Ethics nursing; Social behavior.

\section{Resumen}

Este estudio tiene como objetivo identificar las dimensiones de la violencia en el trabajo del equipo de Enfermería relacionada con los actos negativos. Se trata de un estudio cuantitativo, exploratorio y transversal. Con una muestra estimada de 13.011 profesionales de enfermería, se utilizó un cuestionario revisado de actos negativos. La variable de resultado fue la puntuación del cuestionario, que permitió evaluar la violencia en cuatro dimensiones. Para el análisis de los datos se utilizó el análisis descriptivo mediante medias, desviaciones estándar, valores mínimos y máximo de puntajes para variables continuas y proporciones para variables cualitativas. La tasa de participación fue del 16,4\%, correspondiente a 2.136 profesionales. La descalificación personal y profesional fue la dimensión que obtuvo la mayor media de puntuación seguida, respectivamente, por el acoso laboral, el acoso personal y la intimidación física. A partir de la identificación y puntuación de los actos negativos referenciados en el instrumento aplicado, fue posible identificar las dimensiones de la violencia en la vida cotidiana de los profesionales de enfermería.

Palabras clave: Violencia laboral; Grupo de enfermería; Ambiente de trabajo; Ética en enfermería; Conducta social. 


\section{Introdução}

Discorrer sobre a violência no ambiente de trabalho dos profissionais de Enfermagem fez-se iminente posto que as condições evidenciadas na saúde dos trabalhadores, expostos a condições indignas, devastam qualquer possibilidade de equilíbrio da saúde mental.

Ao tratar das condições de trabalho, é preciso indagar sobre os significados e contextos a respeito de sua precarização e flexibilização, que reverberam nas relações laborais. Nas instituições, expressam-se em formas de organização pautadas na gestão pelo medo, autonomia castrada, práticas participativas forçadas, imposição sutil de autoaceleração, multifuncionalidade, dentre outros métodos voltados ao controle maximizado. Estas características são processos de dominação nos quais se podem constatar: insegurança; competição; desconfiança e individualismo; constrangimento e sequestro do tempo e da subjetividade do trabalhador. Depreende-se, dessa forma, uma série de malefícios do trabalho precário, em especial, na vida profissional e social do trabalhador, que se vê cada vez mais desprotegido do ponto de vista laboral, social e em seus direitos humanos (Franco et al., 2010).

O Brasil contempla um quantitativo relevante de profissionais da Enfermagem, prevalecendo entre os profissionais da área da saúde. Altamente capacitados para atuar em distintos contextos, destinados às práticas de atenção à saúde, não é incomum ultrapassarem as barreiras geográficas para suprir demandas internacionais, fato que mostra o reconhecimento de suas competências técnicas e legais. Várias frentes de trabalho são destinadas à atuação da Enfermagem e não somente a assistencial, entre elas, a gestão, a educação e a pesquisa.

Neste cenário, o trabalho da Enfermagem é pautado no reconhecimento da saúde para as transformações exigidas ao desenvolvimento social, a possibilidade de melhorias da capacidade de organização e o funcionamento do sistema e a solução de problemas de saúde que afetam a grande maioria da população.

Paradoxal quanto à relevância social da Enfermagem, um movimento político, definido como a precarização do trabalho, fundamentado na instabilidade e insegurança, faz parte do universo da Enfermagem por meio da flexibilização de vínculos dos trabalhadores. Esta flexibilização, por sua vez, submete o trabalhador a atender a demandas institucionais frequentes e o penaliza em momentos de crise, o que degrada suas condições de saúde psicofísica.

Recorre-se, assim, à seriedade com a qual a violência no trabalho deva ser imprescindivelmente discutida, analisada e mapeada por meio de incentivo às pesquisas, educação e ações em campos de trabalho.

A violência institucionalizada contextualiza-se na compreensão de que novas relações de trabalho se estabelecem no ambiente capitalista financeiro que vislumbra somente o lucro. Essa violência implícita nas relações de trabalho degrada e controla os comportamentos, os modos de pensar e as decisões do trabalhador vitimado (Souza, 2019).

A identificação da violência na Enfermagem está descrita tanto em estudos que não envolvem especificação de categoria profissional, como em estudos com profissionais de saúde em geral, ou em estudos conduzidos apenas com a equipe de Enfermagem. Aponta-se para o potencial nocivo e oneroso desse fato por ser capaz de ocasionar sofrimento, adoecimento, afastamentos do trabalho e até a morte (Bordignon \& Monteiro, 2016).

Em um estudo que objetivou compreender as vivências dos enfermeiros resultantes da exposição ao assédio moral no ambiente de trabalho, foi evidenciado que estes profissionais se submetem a situações degradantes a fim de protegerem-se e manterem a estabilidade de seu dia a dia e sofrem as consequências do assédio moral (Hagopian et al., 2017).

No contexto relacionado com as situações degradantes no ambiente de trabalho, é necessário buscar estratégias que envolvam a equipe de Enfermagem e os gestores para não banalizar as situações de violência no trabalho a cristalizarem-se nas instituições de saúde como corriqueiras (Silveira et al., 2016). 
Estudo realizado com equipe de Enfermagem mostrou estreita relação entre a violência sofrida pelos trabalhadores da equipe de Enfermagem e a sua associação com burnout e transtornos psíquicos menores em seus ambientes de trabalho (Fontana, 2020).

A relação antagônica entre capital e trabalho é responsável por configurações distintas do ambiente de trabalho mediante os atos individualizados, perversos e mal-intencionados. As certezas da vida do trabalhador transformam-se em incertezas, medos, angústias e instabilidades (Gomes \& Lima, 2019).

Apesar do crescente interesse no tema, ainda são identificados muitos questionamentos e dúvidas com relação à caracterização de situações de violência no trabalho. Um pacto informal de silêncio é induzido pelo medo que os integrantes de uma equipe têm em identificar e apoiar vítimas de violência com a justificativa de manter seus empregos (Hagopian et al., 2017).

Intentar esta pesquisa, abarcando a violência no contexto de quem estima pela saúde da população, faz-se plano de contingência aos profissionais da Enfermagem em respeito à saúde física, mental e seu relacionamento social. Ambientes hostis, impulsionados pela violência do cotidiano neoliberal, trazem repercussões, por vezes, incorrigíveis. Por esse fim, manifestar-se sobre a violência, como o novo risco psicossocial que atinge a maior proporção de profissionais da saúde, foi a proposta deste estudo.

Para tal, ao início do desenho metodológico na proposta do trabalho, a hipótese foi delineada na relação entre os atos negativos e a violência, sendo que as questões foram problematizadas nesta confluência conforme descrito abaixo.

Hipótese do estudo: há uma estreita relação entre os atos negativos e a violência no ambiente de trabalho da Enfermagem.

Questões problematizadas: há correspondência entre os atos negativos que ocorrem no ambiente de trabalho da Enfermagem e a violência? Quais variáveis se associam à percepção dos atos negativos com a violência no ambiente de trabalho da Enfermagem?

\section{Metodologia}

O formulário para a coleta de dados foi estruturado na ferramenta eletrônica Google Forms. Antes de iniciar a coleta com o questionário virtual, foi inserido um Termo de Consentimento Livre e Esclarecido (TCLE), composto por uma página de esclarecimento sobre a pesquisa, além da solicitação de autorização para o uso dos dados. O profissional só teve acesso ao formulário para preenchimento após aceite eletrônico do TCLE, que foi disponibilizado para download e para que o entrevistado pudesse guardar uma cópia.

A população-alvo foi composta por 491.977 trabalhadores de Enfermagem inscritos no COREN-SP e distribuídos em 14 subseções regionais. Ao considerar que 85.904 (17,5\%) profissionais não tinham e-mail válido cadastrado no COREN-SP, restaram 406.073 trabalhadores que compunham a população acessível para o estudo. Estimou-se, considerando $\mathrm{p}=$ proporção máxima esperada de profissionais com relato de exposição à violência institucional, com 17,0\% de prevalência identificada em estudo anterior (Machado et al., 2016), uma amostra de 13.011 profissionais de Enfermagem.

Estabeleceram-se como critérios de inclusão: possuir inscrição ativa no Conselho Regional de Enfermagem do Estado de São Paulo (COREN-SP); dispor de e-mail válido e atuar na categoria por tempo superior a seis meses. Não se aplicaram critérios de exclusão.

Trata-se de um estudo quantitativo, exploratório, transversal. A população-alvo deste estudo foi constituída por profissionais de Enfermagem, sendo estes auxiliares, técnicos e enfermeiros do Estado de São Paulo. A coleta de dados foi realizada no mês de agosto de 2017 mediante três disparos eletrônicos da equipe de TI do COREN-SP. 
Por tratar-se de um estudo com seres humanos, o projeto foi submetido ao Comitê de Ética em Pesquisa da Instituição Proponente para atender à Resolução $n^{\circ} 446 / 12$ do Conselho Nacional de Saúde e foi aprovado pelo número CAEE $n^{\circ}$ 64912317.8.0000.539.

Os dados foram coletados em um formulário estruturado na ferramenta eletrônica Google Forms. O instrumento utilizado para a coleta dos dados foi o Questionário de Atos Negativos Revisado (QAN-R). Trata-se de um inquérito desenvolvido na Noruega, em 1994, e validado no Brasil, em 2011, utilizado para pesquisas objetivas e composto por 22 itens de descrições de comportamentos negativos diretos, como agressão verbal, observações ofensivas e intimidação, bem como os indiretos: isolamento social; difamação e pressão (Dean et al., 2013). Esta escala permite determinar quantas vezes o participante da pesquisa, durante os últimos seis meses, foi submetido a essas condutas por meio da escala Likert.

O total de respostas recebidas para os questionários, ao término da coleta de dados, foi de 2.136. A confiabilidade do QAN-R foi verificada, por meio da avaliação de sua consistência interna, usando o coeficiente Alfa de Cronbach.

Para o cálculo do tamanho da amostra, foi utilizado o programa Open Source Epidemiologic Statistics for Public Health (OPENEPI) - versão 3.01, módulo Sample size. Esse programa utiliza a fórmula (Silva et al., 2017): $n=$ [EDFF*Np (1$\mathrm{p})] /\left[\left(\mathrm{d}^{2} / \mathrm{Z}^{2}{ }_{1-\alpha / 2} *(\mathrm{~N}-1)+\mathrm{p} *(1-\mathrm{p})\right]\right.$.

A análise foi feita tanto para o conjunto da escala, como para cada uma de suas dimensões.

A análise descritiva foi feita por médias, desvios-padrão, valores mínimos e máximos dos escores das variáveis contínuas e proporções para as variáveis qualitativas.

Foi realizado o teste Shapiro-Francia para verificar a aderência do escore QAN-R à distribuição normal. Como a variável apresentou distribuição não paramétrica $(\mathrm{p}<0,001)$, foram utilizados tipos de testes estatísticos para variáveis categóricas.

Para a avaliação dos fatores associados à violência no trabalho, inicialmente, foi realizada a análise bivariada utilizando o teste qui-quadrado. As variáveis que apresentaram $\mathrm{p}<0,20$ no modelo bivariado foram incluídas na modelagem de regressão logística múltipla pelo método stepwise forward e o valor do "p" na análise bivariada determinou a ordem de entrada na modelagem múltipla. Em todas as análises realizadas, foi utilizado o nível de significância de 5\%.

Foi realizada avaliação do QAN-R quanto às suas quatro dimensões da violência:

1 - Assédio relacionado ao trabalho: escore que varie de oito a 40 pontos, composto por oito itens do NAQ: 5, 10, 11, $16,17,18,19$ e 21 ;

2 - Assédio pessoal: escore que varie de sete a 35 pontos, composto por sete itens do NAQ: 2, 6, 7, 8, 12, 13 e 15;

3 - Desqualificação pessoal e profissional: escore que varie de quatro a 20 pontos, composto por quatro itens do NAQ: $1,3,4$ e 14

4 - Intimidação física: escore que varie de três a 15 pontos, composto por três itens do NAQ: 9,20 e 22.

Como as quatro dimensões têm escores de tamanhos diferentes, elas foram convertidas em uma escala que varia de zero a 100 de forma a facilitar a comparabilidade entre as dimensões. Para tanto, para cada dimensão, foram feitos os cálculos seguintes:

a) Cálculo do tamanho da distância do escore (maior pontuação possível ao subtrair a menor pontuação possível);

b) Cálculo do valor de cada ponto da distância (ao considerar a maior pontuação como equivalente a 100);

Cálculo da nova pontuação padronizada (considera a pontuação original ao subtrair o menor valor possível da dimensão e, em seguida, multiplicar pelo valor de cada ponto da distância do escore). 


\section{Resultados}

Na Tabela 1, observa-se que, para o conjunto os itens componentes do QAN-R, o instrumento apresentou coeficiente Alpha de Cronbach de 0,935. A exclusão de qualquer uma das questões que compõem o questionário não proporcionaria melhorias nos resultados.

Tabela 1. Valores do Alpha de Cronbach do QAN-R - por item, profissionais de Enfermagem. São Paulo, São Paulo, Brasil, 2017.

\begin{tabular}{lc}
\hline \multicolumn{1}{c}{ Item } & Alpha de Cronbach \\
\hline 1. Alguém reteve informações que podem afetar o seu desempenho. & 0,934 \\
2. Foi humilhado (a) ou ridicularizado (a) em relação ao seu trabalho. & 0,931 \\
3. Foi obrigado (a) a realizar um trabalho abaixo do seu nível de competência. & 0,934 \\
4. Áreas ou tarefas de sua responsabilidade foram retiradas. & 0,933 \\
5. Espalharam boatos ou rumores sobre você. & 0,932 \\
6. Foi ignorado (a), excluído (a) ou "colocado (a) na geladeira". & 0,931 \\
7. Foram feitos comentários ofensivos sobre a sua pessoa. & 0,932 \\
8. Gritaram com você ou você foi alvo de agressividade gratuita. & 0,931 \\
9. Foi alvo de comportamentos intimidativos. & 0,932 \\
10. Recebeu sinais ou dicas de que você deve pedir demissão. & 0,932 \\
11. Foi constantemente lembrado (a) dos seus erros e omissões. & 0,932 \\
12. Foi ignorado (a) ou foi recebido (a) com uma reação hostil ao aproximar. & 0,931 \\
13. Recebeu críticas persistentes ao seu trabalho ou esforço. & 0,931 \\
14. Suas opiniões e pontos de vista foram ignorados. & 0,931 \\
15. Pessoas com as quais você não tem intimidade lhe aplicaram “pegadinhas”. \\
16. Foi solicitado (a) a realizar tarefas despropositadas. & 0,933 \\
17. Foram feitas alegações contra você. & 0,932 \\
18. Supervisão excessiva de seu trabalho. & 0,931 \\
19. Foi pressionado (a) a não reclamar um direito que você tem. & 0,932 \\
20. Foi submetido (a) a sarcasmos ou alvo de brincadeiras excessivas. & 0,932 \\
21. Foi exposto (a) a uma carga de trabalho excessiva. & 0,931 \\
22. Foi ameaçado (a) de violência ou abuso físico. & 0,935 \\
\hline \multicolumn{1}{c}{ Escala total } & 0,933 \\
\hline
\end{tabular}

Fonte: Autores.

A Tabela 2 apresenta a avaliação da consistência interna de cada uma das dimensões do QAN-R. Os resultados obtidos foram: 1 - assédio relacionado ao trabalho: $\alpha=0,845 ; 2$ - assédio pessoal: $\alpha=0,857 ; 3$ - desqualificação pessoal e profissional: $\alpha=0,743 ; 4$ - intimidação física: $\alpha=0,0,719$. Observa-se que a exclusão de qualquer um dos itens que compõem cada dimensão não proporcionaria melhorias importantes nos resultados. 
Tabela 2. Valores do Alpha de Cronbach do QAN-R - por dimensão e item, profissionais de Enfermagem. São Paulo, São Paulo, Brasil, 2017.

\begin{tabular}{lc}
\hline \multicolumn{1}{c}{ Dimensão/Item } & Alpha de Cronbach \\
\hline 1 - Assédio relacionado ao trabalho. & 0,833 \\
5. Espalharam boatos ou rumores sobre você. & 0,824 \\
10. Recebeu sinais ou dicas de que você deve pedir demissão. & 0,824 \\
11. Foi constantemente lembrado (a) dos seus erros e omissões. & 0,824 \\
16. Foi solicitado (a) a realizar tarefas despropositadas. & 0,821 \\
17. Foram feitas alegações contra você. & 0,820 \\
18. Supervisão excessiva de seu trabalho. & 0,824 \\
19. Foi pressionado (a) a não reclamar um direito que você tem. & 0,843 \\
21. Foi exposto (a) a uma carga de trabalho excessiva. & $\mathbf{0 , 8 4 5}$ \\
Todos os itens & \\
2- Assédio pessoal & 0,836 \\
2. Foi humilhado (a) ou ridicularizado (a) em relação ao seu trabalho. & 0,837 \\
6. Foi ignorado (a), excluído (a) ou "colocado (a) na geladeira". & 0,838 \\
7. Foram feitos comentários ofensivos sobre a sua pessoa. & 0,836 \\
8. Gritaram com você ou você foi alvo de agressividade gratuita. & 0,827 \\
12. Foi ignorado (a) ou foi recebido (a) com uma reação hostil ao aproximar. & 0,832 \\
13. Recebeu críticas persistentes ao seu trabalho ou esforço. & 0,855 \\
15. Pessoas com as quais você não tem intimidade lhe aplicaram "pegadinhas". & $\mathbf{0 , 8 5 7}$ \\
Todos os itens & \\
3 - Desqualificação pessoal e profissional. & 0,727 \\
1. Alguém reteve informações que podem afetar o seu desempenho. & 0,662 \\
3. Foi obrigado (a) a realizar um trabalho abaixo do seu nível de competência. & 0,639 \\
4. Áreas ou tarefas de sua responsabilidade foram retiradas ou substituídas por tarefas mais & \\
desagradáveis ou mais simples. & 0,699 \\
14. Suas opiniões e pontos de vista foram ignorados. & $\mathbf{0 , 7 4 3}$ \\
Todos os itens & \\
4 - Intimidação física & 0,559 \\
9. Foi alvo de comportamentos intimidativos. & 0,722 \\
20. Foi submetido (a) a sarcasmos ou alvo de brincadeiras excessivas. & 0,606 \\
22. Foi ameaçado (a) de violência ou abuso físico. & $\mathbf{0 , 7 1 9}$ \\
\hline Todos os itens & \\
\hline
\end{tabular}

Fonte: Autores.

A Tabela 3 apresenta os resultados obtidos por meio da aplicação do Questionário QAN-R entre os profissionais que participaram do estudo.

Tabela 3. Estatística descritiva do escore global e das dimensões do QAN-R, profissionais de Enfermagem. Estado de São Paulo. São Paulo, São Paulo, Brasil, 2017.

\begin{tabular}{|c|c|c|c|c|c|c|}
\hline Escala/dimensão* & Quant $†$. & Média & Mediana & $\begin{array}{c}\text { Desvio } \\
\text {-padrão }\end{array}$ & Mínima & Máxima \\
\hline Questionário de Atos Negativos Revisado escore & 2.136 & 38,6 & 35,0 & 14,2 & 22,0 & 110,0 \\
\hline 1-Assédio relacionado ao trabalho & 2.136 & 19,4 & 15,6 & 18,1 & 0,0 & 100,0 \\
\hline 2-Assédio pessoal & 2.136 & 18,3 & 14,3 & 17,0 & 0,0 & 100,0 \\
\hline 3-Desqualificação pessoal e profissional & 2.136 & 23,3 & 18,8 & 20,4 & 0,0 & 100,0 \\
\hline 4-Intimidação física & 2.136 & 12,6 & 8,3 & 17,1 & 0,0 & 100,0 \\
\hline
\end{tabular}

* Dimensões com escores padronizados, variando de 0,0 a 100,0 pontos. Escore global variando de 22 a 110 pontos; $\uparrow$ Quant. $=$ quantidade. Fonte: Autores.

A pontuação média de cada item, em cada dimensão do QAN-R, está apresentada na Figura 3. 
Figura 1. Distribuição (média) dos itens do QAN-R, segundo dimensão, profissionais de Enfermagem. São Paulo, São Paulo, Brasil, 2017.

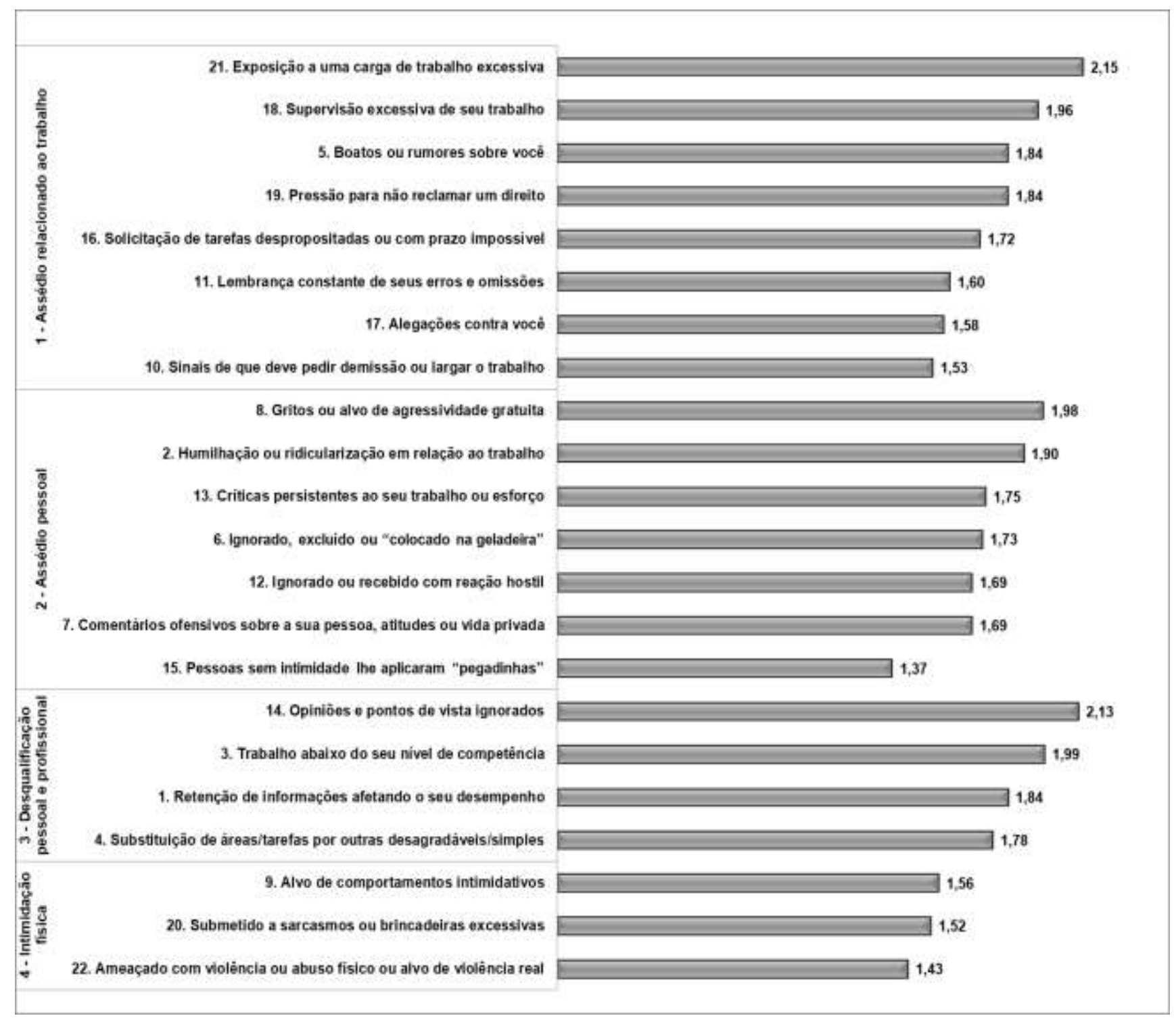

Fonte: Autores.

\section{Discussão}

A Enfermagem contempla aproximadamente $60 \%$ da força de trabalho na área da saúde e produz bens e serviços à sociedade brasileira. Pode-se afirmar que a Enfermagem converge para as Ciências Biológicas, Humanas e Sociais, tendo em vista que a atuação desta categoria não se restringe à assistência e saúde do SUS e suplementar, mas, também, à gestão de instituições sociais e da saúde, educação, pesquisa, consultorias especializadas, atuação em organizações do terceiro setor e atividades liberais da profissão (Associação Brasileira de Enfermagem, 2019)

Ao corroborar as práticas justas e dignas da atuação dos profissionais da Enfermagem, a Declaração Universal dos Direitos Humanos (DUDH) e o Código de Ética dos Profissionais da Enfermagem (CEPE) são os documentos utilizados para a defesa dessas ações.

A DUDH foi proclamada pela Assembleia Geral das Nações Unidas (AGNU) (Nações Unidas Brasil, 1948) em Paris, em 10 de dezembro de 1948, por meio da Resolução nº 217 A (III) da Assembleia Geral, como uma norma comum a ser adotada por todos os povos e nações. Ela estabeleceu, pela primeira vez, a proteção universal dos direitos humanos, estruturada 
em trinta artigos. Ao relacionar a DUDH com este estudo, considera-se como fundamental a exposição do antelóquio, que reconhece a dignidade como inerente a todos os membros da família humana e de seus direitos iguais e inalienáveis.

Com referência ao surgimento do CEPE, estreita relação pode-se compor com a DUDH, uma vez que se soma à sua criação, em meados de 1949, por influência da AGNU e da convenção da Cruz Vermelha em Genebra. No Brasil, o código foi revisado pelo Ministério da Saúde, em 1996, e recentemente vigora o estabelecido pela Resolução COFEN no 564/2017 (Conselho Federal de Enfermagem, 2017), reformulado pelas coordenações do COFEN com a participação dos CORENs.

O código de ética, estruturado em 117 artigos distribuídos entre direitos, deveres, proibições e penalidades, leva em consideração tanto as necessidades quanto os direitos de assistência da Enfermagem para a população, os interesses do profissional e de sua organização.

A DUDH e o CEPE contrariam as práticas de violência, sejam elas estabelecidas por meios físicos ou morais. Ao código de ética de Enfermagem, após recente reformulação, foram incluídas, no Art. 83² as questões do assédio praticado contra outrem, tanto na referência moral quanto sexual. É considerável aplaudir a prosperidade deste avanço, uma vez que o fenômeno assédio, ainda que ocultado, há pouco tempo era praticamente intangível.

Nos artigos da DUDH, lê-se (Nações Unidas Brasil, 1948): "Art. V Ninguém será submetido à tortura nem a tratamento ou castigo cruel, desumano ou degradante".

O CEPE reza (Conselho Federal de Enfermagem, 2017) como direito: "Art. 2 Exercer atividades em locais de trabalho livre de riscos e danos e violências física e psicológica à saúde do trabalhador, em respeito à dignidade humana e à proteção dos direitos dos profissionais de enfermagem”; “Art. 8 Requerer ao Conselho Regional de Enfermagem, de forma fundamentada, medidas cabíveis para obtenção de desagravo público em decorrência de ofensa sofrida no exercício profissional ou que atinja a profissão" e como proibitivo: "Art. 83 Praticar, individual ou coletivamente, quando no exercício profissional, assédio moral, sexual ou de qualquer natureza, contra pessoa, família, coletividade ou qualquer membro da equipe de saúde, seja por meio de atos ou expressões que tenham por consequência atingir a dignidade ou criar condições humilhantes e constrangedoras".

Os profissionais de Enfermagem possuem amplitude de direitos, deveres e proibições que os respaldam ao atuar em situações degradantes que coloquem em risco as suas integridades físicas e morais, assim como a dos usuários do sistema. A estes profissionais, são dados autonomia e dever de fiscalizar o exercício de sua profissão enquanto trabalhadores e contatar os órgãos responsáveis para dar ciência e requerer atuação.

Cabe questionar: por que esse direito é severamente negligenciado pelos profissionais? Ao se pronunciar, a representatividade da categoria é escassa quanto ao conhecimento sobre as deliberações do CEPE em suas profissões e seria ousadia referenciar esta indiferença como estratégia utilizada pelas instituições de saúde (patronos) como meio para alcance dos fins? (mais valia - produtividade)

Os dados obtidos por aplicação do QAN-R mostram que a desqualificação pessoal e profissional apresentou valor médio mais elevado apontado pelos participantes deste estudo, seguido do assédio relacionado com o trabalho e o assédio pessoal. A intimidação física mostrou um valor médio mais baixo.

A violência no trabalho reponta sob profusas conformações e contornos sutis confundem atos mal-intencionados e perversos. No ambiente de trabalho, é imposto, de forma tênue, nas relações reguladas por individualidades, competição e consumismos, sem respeito ou reconhecimento ao próximo (Bordignon \& Monteiro, 2016).

A dimensão relacionada com a desqualificação pessoal e profissional registrada neste estudo pôde ser revelada por meio de afirmações mais apontadas como opiniões e pontos de vista ignorados. Ser obrigado a executar trabalho abaixo de seu nível de competência mostra a necessidade de manifestar que o reconhecimento não deveria ser uma reinvindicação secundária dos que trabalham. 
O nexo de causalidade para que os trabalhadores identifiquem se a ocorrência das falhas na assistência é ocasionada por falta de competência e qualificação ou lapsos nos processos de trabalho e sistema não é explicada para os trabalhadores. A esta incerteza, somam-se sentimentos de angústia e sofrimento, perpetuados pelo medo de ser incompetente, de não estar à altura de suas obrigações ou de mostrar-se incapaz de defrontar, convenientemente, situações incomuns ou incertas que, precisamente, exigem responsabilidade. O reconhecimento do trabalho é reconduzido pelo sujeito ao plano da construção de sua identidade, além da motivação para o trabalho, e a qualidade deste, quando reconhecida, traduz sentimento de alívio, de prazer ou até de elevação (Dejours, 2012).

Diante do exposto, como motivar alguém para o trabalho, quando se ignoram opiniões e pontos de vista e obriga-se o trabalhador a executar tarefa abaixo do nível de competência com o objetivo de desqualificá-lo?

Quanto à dimensão assédio relacionado ao trabalho, mediante apontamentos relacionados com a exposição a uma carga de trabalho e supervisão excessivas, ao comparar os resultados referentes à pesquisa realizada no Estado de São Paulo, observa-se que estar exposto ao risco de agressão, ao excesso de tarefas e à falta de estrutura apropriada para a realização das atividades justificou a insegurança e o desgaste no trabalho referidos por $64 \%$ dos trabalhadores (Hagopian et al., 2017).

Dessa forma, fica evidente que as condições de trabalho desfavoráveis representam fontes potenciais de sofrimento e adoecimento dos profissionais de Enfermagem e remetem a situações de violência, incluindo a violência institucional, preocupante e presente em determinados ambientes de cuidados em saúde (Santos et al., 2011).

Nesta mesma dimensão, ao pressionar para não reclamar um direito, pode-se inferir a representação de um contorno sutil da violência impregnada no ambiente de trabalho sob a forma de intolerância?

Para estudiosos em assédio moral no trabalho (Bordignon \& Monteiro, 2016): "O mais importante é ultrapassar a meta e dar produtividade, não importa como, ou melhor: não se tolera os improdutivos, independentemente das causas. Não se tolera os críticos das jornadas extenuantes. Não se admite que adoeçam. Os dirigentes sindicais e até os filiados são recusados ou mesmo negados como categoria. São novos tempos que impõem mudanças de comportamento, mentalidade e cultura. Entretanto, uma hierarquia rígida, mesmo que travestida de autonomia subsiste”.

As mudanças da reestruturação pós-fordista pactuam com práticas intransigentes, modeladoras de novas posturas, condutas e valores. Mediado pelo estímulo da competição e indiferença ao sofrimento do outro (intolerância), o trabalhador atual torna-se, então, fragmentado. Surgem, dessa forma, colaboradores resilientes, empreendedores, sustentáveis e eticamente corporativos (Piovesan et al., 2019).

Na dimensão assédio pessoal, os itens com maior apontamento foram gritos ou agressividade gratuita e humilhação ou ridicularização com relação ao trabalho.

Em investigação transversal das situações de assédio moral vivenciadas por enfermeiros em seu ambiente de trabalho, realizada com 259 enfermeiros que trabalhavam em unidades básicas de saúde e hospitais da rede pública de João Pessoa, quanto às agressões sofridas no trabalho, a categoria de violência verbal foi a mais apontada pela amostra estudada $(32,76 \%)$ (Cahú et al., 2014).

O estudo supracitado ainda referiu que as deteriorações propositais das condições de trabalho são constatadas pela manipulação do agressor na equipe para assumir posicionamentos contrários aos interesses da vítima, bloqueando o crescimento profissional e tendo como apontamentos criticar o trabalho da vítima de forma injusta e exagerada (47,41\%); insinuar maldades e calúnias (40,52\%) e, publicamente, falar mal do trabalhador (31,03\%) (Cahú et al., 2014).

Ao considerar uma compreensão comum dos documentos apresentados na relação entre a DUDH e o CEPE, o tangenciar da liberdade pessoal e profissional é fundamental para o pleno cumprimento desse compromisso, é necessário e urgente que os trabalhadores (meios) e as instituições (fins) deem mais atenção aos processos de adoecimentos físicos e 
psíquicos que estão arruinando os ambientes de trabalho dos profissionais por meio de atos negativos que corroboram a violência no cotidiano da Enfermagem (Nações Unidas Brasil, 1948; Conselho Federal de Enfermagem, 2017).

Como limitações do estudo, entende-se que este foi realizado exclusivamente no Estado de São Paulo e indica-se estendê-lo para um caráter nacional a fim de verificar a existência do mesmo padrão de resultados. Ele também não abrange, em completude, o tema da violência, uma vez que o foco principal da pesquisa não contemplou a violência proveniente dos usuários do sistema.

A conscientização dos trabalhadores em relação à correta conceituação e correlação das definições, assim como suas repercussões sociais e legais, é sinônima de urgência nas instituições de saúde em suas distintas atuações. Além disso, as instituições devem articular-se com ações que cumpram com o dever ético e profissional de atuar na luta contra a violência no trabalho. Intentar esta descrição, abarcando a violência no contexto de quem zela pela saúde da população, permite apresentar um plano de contingência aos profissionais da Enfermagem com respeito à saúde física, mental e seu relacionamento social. Ambientes hostis, impulsionados pela violência do cotidiano neoliberal, trazem repercussões, por vezes, incorrigíveis.

\section{Conclusão}

A desqualificação pessoal e profissional foi a dimensão que apresentou a maior média de pontuação seguida, respectivamente, pelo assédio relacionado ao trabalho, assédio pessoal e intimidação física. Os atos negativos evidenciados nos cotidianos dos profissionais da Enfermagem foram, em ordem decrescente de pontuação: exposição a uma carga de trabalho excessiva; opiniões e pontos de vista ignorados; gritos ou agressividade gratuita; supervisão excessiva do trabalho; humilhação ou ridicularização em relação ao trabalho; boatos ou rumores sobre o trabalhador. Pressão para não reclamar um direito e ser obrigado a executar trabalho abaixo do nível de competência obtiveram a mesma pontuação e, com menor apontamento, a intimidação física.

A Enfermagem insere-se no contexto da nova morfologia do trabalho desenhada pela dupla face como escolha do indivíduo. Por um lado, os que estão empregados vivenciam a corrosão dos seus direitos sociais pelas ascensões do trabalho informal, intermitente, precarizado e flexível. Estes devem ter disponibilidade perpétua aos olhares invisíveis no ambiente de trabalho que empodera e, por outro lado, no desemprego.

Ao sobrepor o cenário acima com os preceitos do código de ética, que designa, ao exercício profissional, a fundamentação no conhecimento próprio da profissão e nas Ciências Humanas, Sociais e Aplicadas, e é executado pelos profissionais na prática social e cotidiana de assistir, gerenciar, ensinar, educar e pesquisar, é fundamental e urgente considerar a saúde desses trabalhadores no tocante à globalidade dos riscos profissionais.

Torna-se difícil encontrar um espaço para esses trabalhadores ao estearem suas práticas nas relações pautadas em ambientes hostilizados, degradados e expostos a riscos psicossociais.

A violência no trabalho é amoldada sempre sob condições relacionais de alguém ou de um grupo e dirigida a outra pessoa. Neste sentido, é imperioso que as organizações oportunizem maiores espaços de discussão, escuta e atenção no que se refere aos fenômenos violentos, sejam eles explícitos ou sutis.

Articular ações que visem à prevenção mediante orientação, informação e acolhimentos torna-se estratégia necessária para prevenção e combate dos contornos que a violência cinge na vida do trabalhador e na repercussão ao cuidado em saúde. Também são pauta para uma forma de violência a autoagressão e o suicídio.

São necessários esforços específicos por meio do ensino e da educação para a formação de profissionais e a educação continuada dos trabalhadores a fim de promover o respeito e designar a importância dos direitos discutidos. Urge evidenciar o reconhecimento da classe trabalhadora da Enfermagem, que é composta por profissionais responsáveis pelo cuidado à população brasileira. 
Research, Society and Development, v. 10, n. 8, e39310817356, 2021

(CC BY 4.0) | ISSN 2525-3409 | DOI: http://dx.doi.org/10.33448/rsd-v10i8.17356

\section{Referências}

Associação Brasileira de Enfermagem. (2019). Enfermagem: técnica e científica, mas não humana e social? ABEn.

Bordignon, M., \& Monteiro, M. I. (2016). Violence in the workplace in nursing: consequences overview. Revista Brasileira de Enfermagem, 69(5), 939-942.

Cahú, G. R. P., Costa, S. F. G., Costa, I. C. P., Batista, P. S. S., \& Batista, J. B. V. (2014). Moral harassment experienced by nurses in their workplace. Acta Paulista de Enfermagem, 27(2), 151-156.

Conselho Federal de Enfermagem. (2017). Código de Ética dos Profissionais de Enfermagem. COFEN.

Dean, A. G., Sullivan, K. M., \& Soe, M. M. (2013). Epidemiologic statistics for public health. Atlanta: OpenEpi.

Dejours, C. (2012). A banalização da injustiça social. FGV.

Franco, T., Druck, G., \& Seligmamm-Silva E. (2010). As novas relações de trabalho, o desgaste mental do trabalhador e os transtornos mentais no trabalho precarizado. Revista Brasileira de Saúde Ocupacional, 35(122), 229-248.

Fontana, T. R. (2020). A violência no cotidiano de trabalho da enfermagem e os usos de si no enfrentamento. Revista Vivências, 16(30), 99-114.

Gomes, L. F. G., \& Lima, M. E. A. (2019). Workplace bullying in the university contexto study with an IFES in the interior of Minas Gerais. Cadernos de Psicologia Social do Trabalho, 22(1), 1-14.

Hagopian, E. M., Freitas, G. F., \& Baptista, P. C. P. (2017). Moral harassment in nursing working. Revista Baiana de Enfermagem, 31 (1), e16588.

Machado, M. H., Santos, M. R., Oliveira, E., Wermelinger, M., Vieira, M., Lemos, W, Lacerda, W. F., Aguiar Filho, Souza Junior, P. B., Justino, E., \& Barbosa, C. (2016). Condições de trabalho da enfermagem. Enfermagem em Foco, 7(Spe), 63-76.

Nações Unidas Brasil. Resolução ONU $n^{\circ}$ 217-A, de 10 de dezembro de 1948. (1948). Considerando que o reconhecimento da dignidade inerente a todos os membros da família humana e dos seus direitos iguais e inalienáveis constitui o fundamento da liberdade, da justiça e da paz no mundo. Brasília: Nações Unidas Brasil.

Piovesan, V. H. B., \& Pansera-De-Araújo, M. O. (2019). The oti-pessimism in Morin and the perspectives on the future of humanity. Revista Eletrônica do Mestrado em Educação Ambiental, 36(1), 287-304.

Santos, A. M. R., Soares, J. C. N., Nogueira, L. F., Araújo, N. A., Mesquita, G. V., \& Leal, C. F. S. (2011). Institutional violence: routine experiences of the nursing team. Revista Brasileira de Enfermagem, 64(1), 84-90.

Silva, I. V., Aquino, E. M. L., \& Pinto, I. C. M. (2017). Psychometric properties of the negative acts questionnaire for the detection of workplace bullying: an evaluation of the instrument with a sample of state health care workers. Revista Brasileira de Saúde Ocupacional, 42 , e2.

Silveira, J., Karino, M. E., Martins, J. T., Galdin, M. J. Q., \& Trevisan, G. S. (2016). Violence at work and measures for self-protection: nursing staff conception. Journal of Nursing \& Health, 6(3), 436-446.

Souza, E. A. (2019). Moral harassment and labor reform: interview with Margarida Barreto. Revista Katálysis, $22(3), 641-651$. 